\title{
Barrios cerrados: patrones de localización de tipologías y modelos de estructura urbana. Caso de estudio: Ciudad de Córdoba (Argentina) 1991-2010
}

\author{
Gated communities: typology location patterns and urban structure models. Case \\ Study: City of Córdoba (Argentina), 1991-2010
}

\author{
Martín Lemma \\ martinlemma@conicet.gov.ar \\ Centro de Estudios Urbanos y Regionales (CEUR)- \\ CONICET, Argentina
}

Recepción: 20 Abril 2020

Aprobación: 13 Julio 2020

Publicación: 02 Noviembre 2020

Cita sugerida: Lemma, M. (2020). Barrios cerrados: patrones de localización de tipologías y modelos de estructura urbana. Caso de estudio: Ciudad de Córdoba (Argentina) 1991-2010. Geograficando, 16(2), e073. https://doi.org/10.24215/2346898Xe073
Resumen: En la Ciudad de Córdoba se verifica la materialización del modelo de fragmentación residencial que se daen varias ciudades latinoamericanas. El objetivo de este artículo es estudiar los patrones de localización de los barrios cerrados en la Ciudad de Córdoba para construir una matriz de análisis que permita discutir dichas transformaciones en el modelo de estructura urbana. La metodología de base empleada en este artículo es el análisis documental de documentos visuales, el mismo es realizado mediante herramientas de la morfología urbana. Los resultados permiten evidenciar la intensificación del modelo de fragmentación urbana entre 1990 y 2010, y su asentamiento casi exclusivo sobre los sectores de la ciudad con mayores ingresos. Lo anterior pone en disputa algunas de las nociones sobre la novedad de los modelos de estructura urbana en ciudades latinoamericanas a partir de los años 70 .

Palabras clave: Barrios cerrados, Morfología urbana, Ciudades intermedias, Fragmentación, Polarización.

Abstract: The City of Córdoba evidences the materialization of the residential fragmentation model taking place in several Latin American cities. The aim of this article is to study location patterns in gated communities from the City of Córdoba to build an analysis matrix that will allow the study of transformations in the urban structure model. The base methodology used in this article is documentary analysis of visual documents, carried out by urban morphology tools. Results show an intensification of the urban fragmentation model between 1990 and 2010, and its almost exclusive settlement on city areas with the highest income. This disputes some notions about the novelty of urban structure models in Latin American cities since the 1970s.

Keywords: Gated communities, Urban morphology, Intermediate cities, Fragmentation, Polarization. 


\section{INTRODUCCIÓN}

Diversos autores coinciden en que los fragmentos son la nueva figura urbana que deriva de la globalización y que reproduce las desigualdades globales dentro de la estructura del espacio urbano (Borsdorf, 2003; Carmona y Burgess, 2001; Ciccolella, 2014; Janoschka, 2002; Secchi, 2005). Para entender las especificidades del proceso de fragmentación urbana en el contexto latinoamericano, es necesario introducir estas transformaciones dentro de un proceso histórico del entorno construido.

Para los fines de este artículo, resulta útil comenzar por los estudios que un grupo de geógrafos alemanes realizaron sobre una serie de importantes ciudades latinoamericanas (Borsdorf, 2003; Janoschka, 2002; Meyer y Bähr, 2001). Dichos estudios permiten analizar y comparar las transformaciones territoriales latinoamericanas a la par de los cambios en el contexto de desarrollo propio de cada período. El estudio que resulta de la puesta en común de estos trabajos sobre distintas ciudades aporta cuatro "modelos" de ciudad latinoamericana: la época colonial estructurada en función de la pendiente centro-periferia (de 1500 a 1820); la primera fase de urbanización, cuyo principio estructural es la linealidad (de 1820 a 1920); la segunda fase de urbanización, cuyo principio estructural es la polarización (de 1920 a 1970); y la reestructuración, conformada espacialmente mediante los fragmentos (desde 1970 hasta hoy)(Borsdorf, 2003).

Según esta periodización, en las últimas décadas las metrópolis latinoamericanas han experimentado considerables transformaciones físico-espaciales, lo cual ha llevado a la conformación de una nueva manera de organización de las funciones y elementos socioespaciales urbanos en una escala más reducida respecto de la polarización ciudad rica - ciudad pobre(característica del período anterior). En concreto, lo que observan estos geógrafos alemanes es que diversos elementos urbanos (tanto residenciales como comerciales, de ocio, laborales, etc.) suelen ser localizados en entornos que no necesariamente reproducen las características del modelo de riqueza de estos elementos; estos elementos se conectan entre sí a través de una red de autovías en la que el automóvil individual es el vehículo predominante.

Haciendo una comparación de los últimos dos modelos de desarrollo, Borsdorf (2003) señala que solamente dos principios estructurales del pasado todavía continúan vigentes en la ciudad contemporánea: la tendencia sectorial-lineal y el crecimiento celular. Dentro de los principales cambios con el ciclo anterior, aparece el cambio de escala, que hace referencia a que la división ciudad rica - ciudad pobre durante la segunda fase de urbanización se daba en la escala de lo urbano, definiendo un sector de la ciudad para cada grupo económico (Sabatini y Cáceres, 2001). Según Borsdorf (2003), durante el ciclo en cuestión la localización de los nuevos fragmentos dentro del entramado urbano llama a encuadrar en una escala menor que permita visualizar los contrastes socioeconómicos abruptos dentro de la trama urbana. En otras palabras, con la implantación de enclaves de riqueza en toda la periferia la división socioeconómica principal deja de darse a escala de la ciudad (centro-periferia) para darse a escala de sector, en la quelas diferencias socioeconómicas se observan en ambas áreas.

Según Janoschka (2002), la estructuración y desarrollo del espacio urbano de las ciudades latinoamericanas se ha resuelto, entonces, con la utilización de estructuras insulares que abarcan cuatro dimensiones: riqueza, producción, consumo y precariedad. Los artefactos urbano-arquitectónicos más distintivos son los barrios cerrados, los parques industriales, los centros comerciales y los barrios de vivienda social de bajos recursos (ya sean formales o informales).El elemento de unión entre estos artefactos y el entorno urbano son las vías de transporte masivo metropolitano, en especial las autopistas y autovías.

Según el autor, la localización de los artefactos de las tres primeras dimensiones dentro de las áreas metropolitanas responde en gran medida a la existencia de la infraestructura de transporte; por su parte, la localización de la dimensión de la precariedad queda determinada por el patrón de valor del suelo.

No obstante, Segura (2014) señala que existen otras posturas en el debate sobre cómo interpretar las transformaciones de la ciudad a partir del creciente rol de las inversiones privadas como ordenadores del espacio urbano. En este sentido, el autor se pregunta si la estructura urbana de las ciudades latinoamericanas 
se ha reconfigurado efectivamente hacia un nuevo modelo fragmentado. Además de las observaciones de los geógrafos alemanes, Segura (2014) presenta, en primer lugar, la posición de Duhau y Giglia (2008), Ciccolella (2014) y De Mattos (2010), que -en contraposición con los alemanes- señalan la intensificación de la división social del espacio urbano y de los patrones de segregación.

La posición de Duhau y Giglia (2008) argumenta que para entender los impactos de la globalización sobre el territorio urbano latinoamericano es necesario introducir una mirada histórica de largo plazo que tome en cuenta ciertos procesos socioeconómicos y socioespaciales de largo alcance, que se gestan como resultado de la introducción del modelo económico fordista. El propósito es incorporar una mirada que permita identificar qué es lo verdaderamente novedoso dentro de las transformaciones de la estructura urbana.

Segura (2014) también identifica una posición intermedia, la de Caldeira (2007) para el caso de São Paulo; ésta señala tendencias múltiples que se sobreimprimen sobre el patrón de asentamiento centro (ciudad rica) y periferia (ciudad pobre) que caracterizó a la metrópolis entre 1940 y 1970. En este sentido, Caldeira (2007) apunta que es posible identificar la coexistencia de esta división junto con patrones como la polarización, la dispersión y la fragmentación. En el trabajo de Caldeira (2007), esto se ejemplifica con el proceso de abandono del centro por parte de sectores de la población de ingresos altos y medios, y su localización en la periferia o en áreas intermedias; esto generó una mayor proximidad entre clases dentro de un mismo sector urbano, pero despertó la necesidad de materializar barreras físicas y la intensificación de los sistemas de control.

En el contexto latinoamericano, los estudios urbanos sobre fragmentación y barrios cerrados son realizados -en su mayoría - sobre ciudades de escala metropolitana en términos demográficos; esto significa aglomeraciones urbanas de más de 4 o 5 millones de personas, según el relevamiento realizado por Usach y Garrido Yeste (2009). No obstante, es posible encontrar una serie de trabajos académicos que estudia esta problemática sobre ciudades con una menor cantidad de habitantes (Borsdorf, Sánchez y Marchant, 2008; J. C. Frediani, 2008, 2009; J. C. Frediani y Matti, 2007; Maya, 2017; Oliveira Goulart y De Oliveira Gonçalves, 2019; Pallud, 2010; Prieto, 2012; Roitman, 2005).En este artículo interesa trabajar en particular con los barrios cerrados, uno de los artefactos de la dimensión de riqueza que cobra relevancia en las ciudades latinoamericanas a partir de mediado de los años 70 . Desde una perspectiva morfológica, un barrio cerrado es:

\begin{abstract}
Urbanizaciones de dos o más viviendas que cuentan con una infraestructura común, se encuentran delimitados por un cerramiento perimetral que los separa del espacio público y poseen espacios para el control interno y de accesos. Las viviendas de un barrio cerrado pueden ser casas (viviendas unifamiliares) o departamentos separados de los limites municipales (viviendas multifamiliares); su cerramiento perimetral puede ser materializado mediante muros o alambrados; su infraestructura incluye calles y puede incluir áreas verdes, equipamientos deportivos, áreas infantiles, piscinas, áreas de ocio y áreas sociales como club house; y los espacios de ingreso pueden ser barreras o puertas(Lemma, 2020b).
\end{abstract}

\title{
Barrios cerrados e intervenciones habitacionales públicas en la Ciudad de Córdoba
}

La elección de la Ciudad de Córdoba como caso de estudio persigue el propósito de contribuir a los conocimientos de la problemática de la fragmentación en ciudades menores a la escala metropolitana. ${ }^{1}$ Más aún, se busca reforzar la producción en torno a lecturas morfológicas.

En la Ciudad de Córdoba, la construcción de barrios cerrados ocurre a partir de 1991, luego de la sanción de la Ordenanza No 8606/91: Urbanizaciones Residenciales Especiales (URE) (Municipalidad de Córdoba, 1991). Las URE se caracterizan por ser una modalidad normativa que posibilita la construcción de urbanizaciones de baja densidad, principalmente sobre el área periférica de la ciudad. La aprobación de esta norma sucede en el marco de un intento de la gestión municipal por responder a las demandas del sector inmobiliario residencial.

Lemma $(2017,2020 a)$ señala que esta normativa irrumpe disruptivamente dentro de un proceso de planificación y regulación del suelo urbano cuyo objetivo más consensuado -a pesar de los cambios políticos en la gestión municipal- era el freno a la expansión de la mancha urbana bajo la modalidad de baja densidad. 
En este sentido, el autor denota una tensión entre los objetivos de los documentos de planificación y el proceso de modificaciones en el marco normativo que regula la forma urbana.

Las estrategias de ordenamiento de los barrios cerrados no son parte de los documentos de planificación urbana hasta la presentación, en el año 2003, de la Formulación de lineamientos alternativos para el plan urbano ambiental (FLA-PUA) (Municipalidad de Córdoba, 2003); hasta entonces, sólo es posible encontrar enunciados referidos a establecer áreas de delimitación para la construcción de nuevas urbanizaciones (Lemma, 2017, 2020a).

En el año 2006 se aprueba la Ordenanza No 11068 (Municipalidad de Córdoba, 2006), que determina un área de exclusión para las URE que comprende principalmente un territorio municipal contiguo no urbanizado de la periferia hacia el sur, sureste, este y noreste (Lemma, 2020a). El fundamento de esta decisión es la preservación del suelo con un uso predominantemente rural, productivo e industrial. A su vez, se trata de un área donde -si bien ya había diferentes tipos de urbanizaciones cerradas construidas- la población que la habitaba era, mayoritariamente, de bajos recursos económicos.

Si bien las URE representan un caso significativo y fácilmente identificable por la existencia de la normativa que las regula, Lemma (2020a, 2020b) identifica otras tres tipologías de barrios cerrados en la Ciudad de Córdoba a partir de una perspectiva morfológica: los barrios cercados, las casonas y las torres (Figura 1).

\section{FIGURA 1}

Fotografías representativas de cada tipología de barrio cerrado en Córdoba, 1991-2010

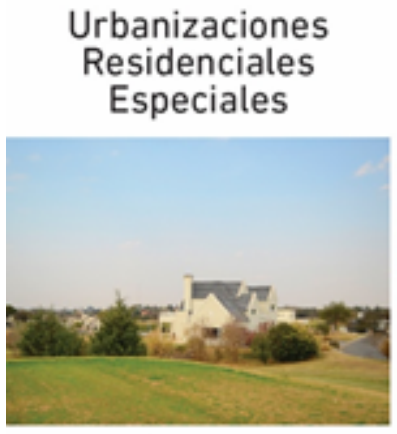

Lomas de los Carolinos
Barrios Cercados

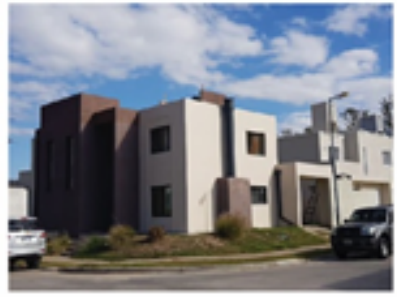

Claros del Bosque
Casonas

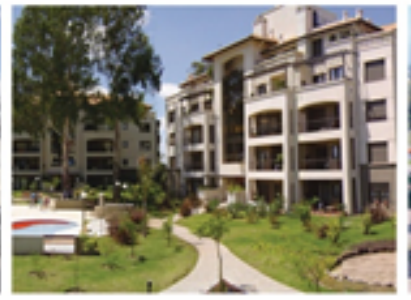

Casonas del Sur
Torres

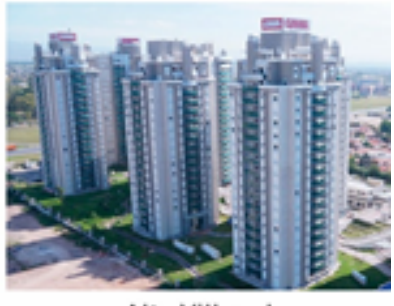

Alto Villasol

Fuente: Lemma (2020a)

Los barrios cercados son urbanizaciones con o sin planes de vivienda, construidos bajo normativas de barrios abiertos (que tienen menor demanda de espacios abiertos públicos y de regulaciones internas); sin embargo, presentan cerramiento perimetral y control de acceso, lo cual implica una trasgresión normativa. Las casonas son conjuntos de viviendas agrupadas en uno o más bloques de perímetro libre y de hasta cinco plantas (planta baja más cuatro pisos). Las torres son conjuntos similares a las casonas, pero con edificaciones de más de cinco plantas.

Un análisis preliminar sobre la localización de la producción residencial pública y la privada realizado por Marengo (2004) infiere que, en la Ciudad de Córdoba, las propuestas habitacionales públicas se localizan sobre los sectores de la ciudad que concentran mayor cantidad de población en situación de pobreza y mayores índices de población con Necesidades Básicas Insatisfechas (NBI), a la par de que las intervenciones de los principales desarrolladores urbanos eligen los sectores de más alto ingresos.

En concreto, las intervenciones estatales se localizan en dos sectores: el primero, aledaño a la Av. Circunvalación y en un arco que se extiende en sentido de las agujas del reloj entre el noroeste y el sureste de la ciudad; el segundo, en el suroeste y mayoritariamente por fuera de dicha avenida, con intervenciones sobre los bordes del barrio Villa del Libertador. Estas intervenciones, que corresponden al programa habitacional "Mi Casa, Mi Vida", persiguieron principalmente el objetivo de relocalizar barrios urbanos informales y villas del centro de la ciudad en ciertos lugares de la periferia. Estos lugares corresponden a fracciones censales con los 
mayores porcentajes de NIB de la ciudad. Se trata de valores que, durante el período de análisis, se encuentran entre el 12 y el 40\% (Provincia de Córdoba, 2001, 2010).

Frente a esta situación, surgen los siguientes interrogantes. ¿Dónde se localizan las intervenciones de barrios cerrados en la Ciudad de Córdoba? ¿Qué patrones de localización es posible observar? ¿Qué cambios produce la aparición de barrios cerrados en el modelo de estructura urbana cordobesa?

En consecuencia, el objetivo de este artículo es estudiar los patrones de localización de los barrios cerrados en la Ciudad de Córdoba para construir una matriz de análisis que permita discutir dichas transformaciones en el modelo de estructura urbana.

\section{Metodología}

La metodología de base empleada en este artículo es el análisis documental, en particular, de documentos visuales, de acuerdo con la clasificación de Valles (1999); dicho análisis es realizado mediante herramientas de la morfología urbana.

Los documentos visuales con los que se trabajó son fotografías satelitales de distintos momentos dentro del período de análisis, aportadas por la Dirección de Catastro de la Municipalidad de Córdoba, Google Earth Pro, Wikimapia y OpenStreetMap.

La elaboración del material gráfico propio fue realizada con sistema de información geográfica de acceso libre QGIS 3.4 y la postproducción, con Adobe Illustrator 2019.

El relevamiento sobre estas fotografías satelitales del ejido municipal fue realizado con el propósito de identificar aquellos casos que cumplieran con la definición y la clasificación tipológica de Lemma (2020b, 2020a).

Durante las dos décadas del período de análisis, la Ciudad de Córdoba mantuvo una población entre 1,1 y 1,3 millones de personas (INDEC, 2001, 2010). Por lo tanto, corresponde adjudicarle la categoría de ciudad grande o intermedia según las clasificaciones aportadas por Usach y Garrido Yeste (2009), lo cual la hace de interés para el estudio en cuestión.

El ejido municipal de la Ciudad de Córdoba tiene una forma cuadrada de $24 \mathrm{~km}$ de lado (es decir, una superficie de $576 \mathrm{~km}^{2}$ ) y se asienta sobre un terreno relativamente llano, al este de una cadena montañosa denominada Sierras Chicas. Su estructura urbana se caracteriza por estar atravesada por un importante número de vías de circulación radial que comunican el centro de la ciudad con su periferia, su área metropolitana y el resto de la homónima provincia.

Por sus extensos límites administrativos, presenta un caso interesante de estudio ya que hacia su interior es posible identificar áreas urbanas, rurales, productivas, industriales y reservas ecológicas. Este contexto habilita el estudio de los patrones de locación en la estructura urbana compleja y diversa.

El estudio toma como recorte temporal un período que comienza en el año 1991 (año en que se sanciona la primera normativa de la ciudad para la construcción de barrios cerrados y en el que comienzan a construirse los primeros casos) y abarca dos períodos de una década cada uno. El primer período va desde 1991 a 2000 y el segundo desde 2001 hasta 2010. A partir de 2010, cambian la dinámica de localizaciones de barrios cerrados y las características funcionales y morfológicas de estos, como resultado de la implementación de los convenios urbanísticos. Dicha dinámica requiere un análisis particularizado que escapa a los fines de este artículo.

Este recorte permite marcar un claro sesgo entre la forma de organización interna de las tipologías imperantes en cada período, a la vez que -por tratarse de una cantidad equivalente de años- habilita la realización de comparaciones más directas entre ambos períodos. Complementariamente, las fechas coinciden con la disponibilidad de datos censales del INDEC, lo cual posibilitó la realización de otros análisis dentro del proyecto marco al cual sirve este estudio. 


\section{Patrones MÚLtiPles E INTENSIFicaCión DE LA POLARIZACión}

A continuación, se exponen los resultados del relevamiento y sistematización de la información obtenida a partir del análisis de las fotografías satelitales. Estos se encuentran divididos por tipologías y ordenados cronológicamente a partir del primer caso de cada tipología.

\section{Urbanizaciones Residenciales Especiales}

Es posible identificar 24 URE, 15 construidas en el primer período y 9 en el segundo. En la Figura 2 se observa la localización de las URE dentro del ejido municipal cordobés. En esta figura se logra dilucidar cuatro corredores radiales, que funcionan como nexo entre el centro de la ciudad y la periferia. Por lo general, las URE se localizan en vínculo directo con las vías de circulación que estructuran los corredores. Los cuatro corredores identificados son:

- Corredor noroeste. Históricamente es el primero en tomar fuerza como corredor. Esto está asociado a una serie de factores, como la disponibilidad de lotes vacantes antes de 1991 entre un área ya urbanizada por un sector de nivel socioeconómico alto (corredor Av. Ricardo Rojas - Av. Recta Martinolli) y con buen desarrollo comercial-administrativo, y dos reservas naturales (la más grande perteneciente al ejército y la otra, el Parque San Martín). Además, al momento de la materialización de las URE de este corredor esta zona contaba con buenas características naturales, como relieves, vegetación y cursos de agua como el Río Suquía o tramos del Canal Maestro Sur.

- Corredor Sur. Este corredor tiene su auge durante el segundo período y está asociado también a la expansión residencial de un sector socioeconómicamente alto, consolidado en Barrio Jardín. Las URE de este corredor se localizan justamente en el área de extensión que proyecta este barrio hacia la periferia de la ciudad, asociadas a los corredores del Camino a San Antonio, Camino a San Carlos y Camino a 60 Cuadras. Las primeras urbanizaciones en esta zona son la U07 (Fortín del Pozo) y la U03 (Jockey Club).

- Corredor Suroeste. A diferencia de los anteriores corredores, este es más disperso; no presenta la misma claridad ni focos que sobresalgan. A excepción de la URE de Manantiales, todos los barrios del corredor fueron construidos durante el segundo período. El eje al que responden es el conformado por la Av. Armada Argentina - que conecta la Ciudad de Córdoba con la ciudad de Alta Gracia- y el arroyo La Cañada.

- Corredor Oeste. Es un corredor que une las ciudades de Córdoba y Villa Carlos Paz con la Ruta Nacional No 20. Una sola URE, U16 (Siete Soles), se localizó sobre este corredor recién durante el segundo período y su ocupación de lotes fue muy baja (menor al 25\%). Este corredor presenta poca disponibilidad de lotes dentro del ejido municipal, debido a que los lotes al norte de la ruta están protegidos normativamente por reservas naturales militares y la Escuela de Aviación Militar.

Algunas cuestiones que también se pueden evidenciar en la Figura 2 son las siguientes: primero, a partir del 2001, no se construyen nuevas URE sobre el corredor noroeste, mientras que hay un auge en el corredor sur; segundo, de las 24 URE, sólo siete están dentro del anillo delimitado por la Av. Circunvalación, aunque todas están muy cercanas a ella; y por último, la pieza gráfica permite observar que existe un importante sector del ejido municipal donde no es posible encontrar ninguna URE. Este sector representa más de la mitad del ejido municipal y puede observarse al trazar una diagonal imaginaria entre el vértice noroeste y el vértice sureste. 
FIGURA 2

Localización de las Urbanizaciones Residenciales Especiales en el Municipio de Córdoba según período (1991-2010)

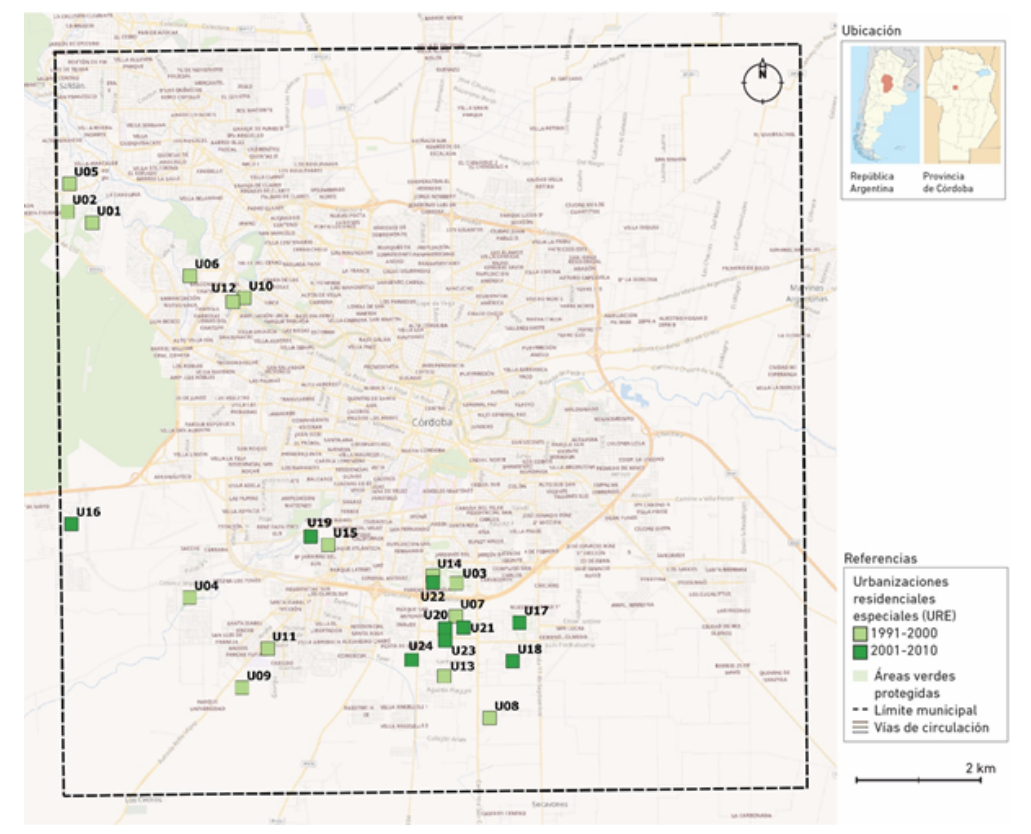

Fuente: Elaboración propia a partir de imágenes satelitales disponibles en Google Earth Pro

\section{Barrios Cercados}

Es posible identificar 60 barrios cercados: 15 construidos en el primer período y 45 en el segundo, es decir, tres veces más cantidad. En la Figura 3 se observa la localización de los barrios cercados dentro del ejido municipal cordobés. En líneas generales, quedan conformados dos sectores que están atravesados de diversos corredores viales radiales. Los barrios cercados no necesariamente se encuentran adyacentes a vías principales de circulación, pero sí cercanos a ellas. Los dos sectores identificados son:

- Sector Noroeste. El área de este sector conforma un arco hacia el noroeste, que está insinuado por la Av. Duarte Quirós y la Av. Rafael Núñez; los 44 Barrios Cerrados que conforman este sector se localizan tanto hacia los límites del ejido municipal como cercanos al centro. En este sector se puede observar que los 15 barrios cercados del primer período se concentran en tres zonas diferentes: el barrio Valle Escondido, la zona cercana a la Av. Manuel de Falla y el barrio Portón de Piedra. El éxito de este sector radica, en gran medida, a su proximidad con buenas características paisajísticoperceptuales, como los relieves, la vegetación y los cursos de agua.

- Sector Sur. En este sector se construyen 16 barrios cercados próximos a la Av. Circunvalación, que conforman un arco que se extiende desde el suroeste al sureste. A su vez, la Av. Circunvalación divide las localizaciones en dos grupos de ocho barrios: el primero corresponde a los barrios que quedan dentro y respeta la amplitud del arco; mientras que el segundo, los que están por fuera, está más concentrado en un área que se superpone al corredor sur de las URE. Lo relevante de esta división es que también permite distinguir entre los barrios con un alto o medio-alto nivel de ocupación (los de dentro delanillo vial) y los que tenían una baja o muy baja ocupación en 2010 (fuera del anillo vial). 
FIGURA 3

Localización de los Barrios Cercados en el Municipio de Córdoba según período (1991-2010)

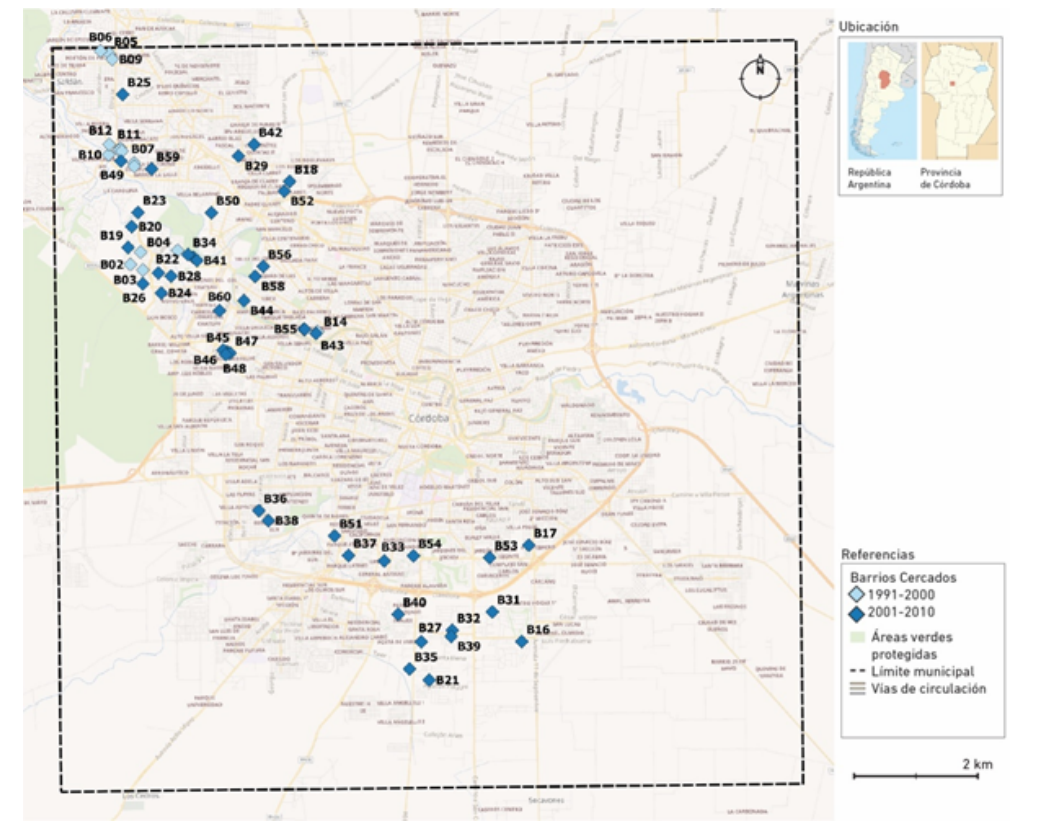

Fuente: Elaboración propia a partir de imágenes satelitales disponibles en Google Earth Pro

La Figura 3 también permite observar el éxito en el sector noroeste de la tipología de barrios cercados, que en el segundo período llegó a consolidarse y ampliar su área de influencia, y ocupó incluso lugares más céntricos que en el primer período. Otra situación que se evidencia es el mayor grado de concentración de los barrios del sector noroeste respecto de los del sur. La Figura 3 también muestra que las dos terceras partes de los barrios cercados construidos se ubicaron fuera de la Av. Circunvalación.

\section{Torres}

Es posible identificar 15 torres, 2 construidas en el primer período y 2 en el segundo. En la Figura 4 se observa la localización de las torres dentro del ejido municipal cordobés. Es posible conformar las siguientes tres categorías para caracterizar los patrones de localización de las torres:

- Anillo Pericentral. Con ocho casos, es la localización predilecta para esta tipología y también donde se localizan los dos primeros casos, ambos del primer período. La localización de estos complejos forma un anillo que rodea el centro de la ciudad, en los límites con barrios pericentrales como Cofico, Güemes, Alberdi o Alta Córdoba. Se trata de barrios históricos mayormente consolidados, con altos valores de urbanidad. La mayor tensión dentro de este anillo se da hacia el noroeste.

- Corredor Av. Colón. Los cuatro complejos de este corredor se localizan sobre o muy próximos a la dicha avenida y llegan a su intersección con la Av. Circunvalación. Es una de las vías radiales de ingreso al centro con mayor flujo y, también, donde existieron planes para construir una línea de transporte subterráneo durante los años 2000.

- Corredor Av. Rafael Núñez. Los tres complejos de este corredor se localizan próximos a dicha avenida, que en la ciudad funciona como un importante centro comercial lineal que atraviesa un área residencial de sectores de altos y medios ingresos. Dos de las torres son parte del Complejo Dinosaurio, un gran centro comercial y recreativo que cuenta con usos como cines, supermercado, centro de eventos, hotel, etc.

Resulta necesario aclarar que los patrones de asentamiento de las torres no conforman figuras tan claras como ocurría con las otras tipologías. Una explicación posible de esto es la menor cantidad de casos en comparación con las URE y los Barrios Cerrados. En este sentido, podría argumentarse que existen dos torres (la T12 y la T15) que pertenecen tanto al corredor Av. Colón como al Anillo Pericentral. 
FIGURA 4

Localización de las torres en el Municipio de Córdoba según período (1991-2010)

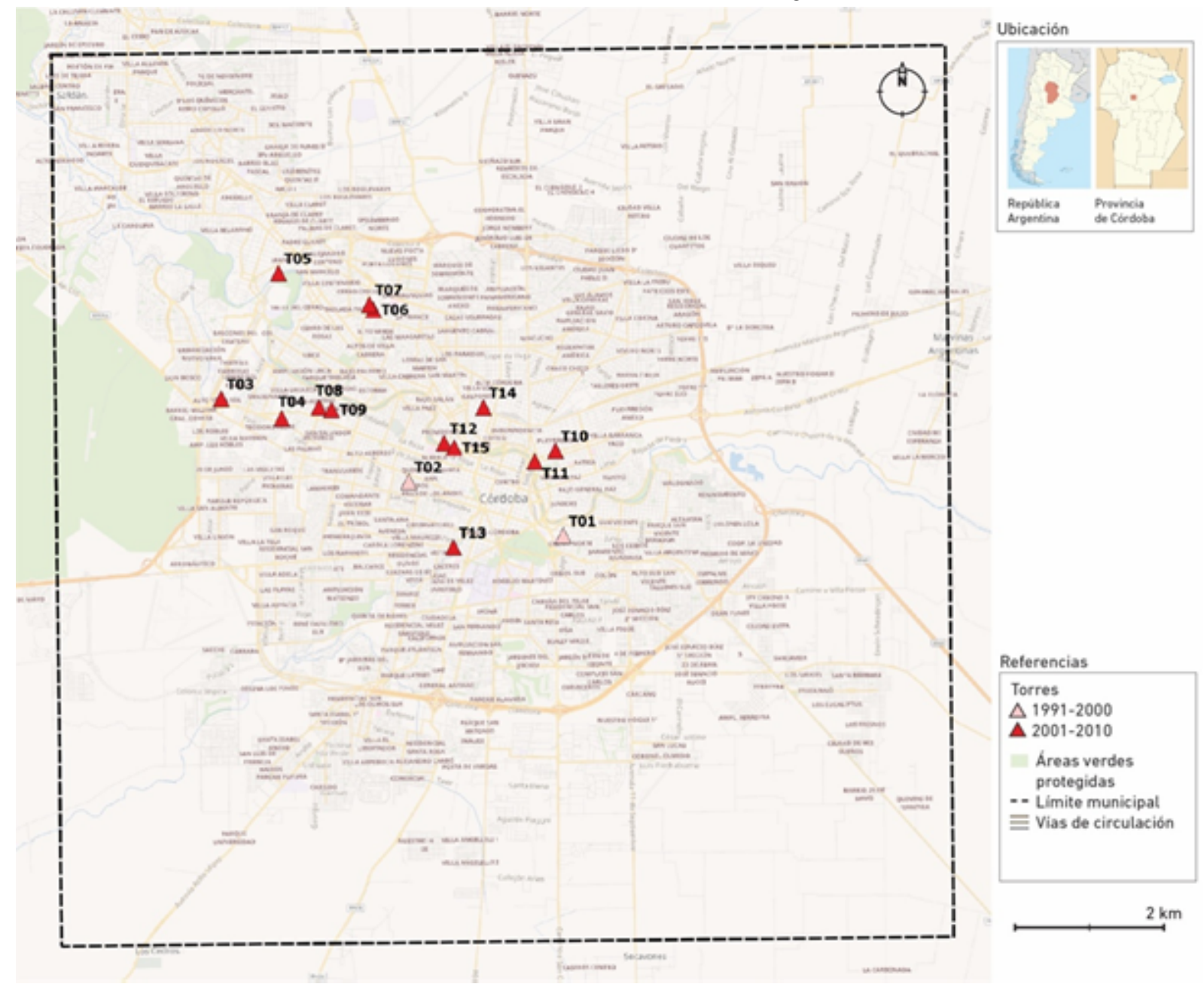

Fuente: Elaboración propia a partir de imágenes satelitales disponibles en Google Earth Pro

Todos los casos se sitúan en estrecho vínculo con una o más arterias principales de circulación, como la Av. Colón o la Av. Intendente Mestre, que permite el tránsito a orillas del Río Suquía y que aporta buenas características paisajístico-perceptuales, como los relieves, vegetación y un importante curso de agua. Además, todas las torres están localizadas en zonas principalmente residenciales de clase media y media-alta, aunque aparecen otros usos de escala sectorial, y también todas están dentro del anillo delimitado por la Av. Circunvalación, a excepción de la T05 (Chateau Village).

En líneas generales, todas las torres están en entornos urbanos consolidados y con buenos servicios e infraestructura urbana; aun así, también aparecen rodeados de lotes vacantes en algunos casos. Inicialmente, los predios donde se construyeron estos emprendimientos también eran lotes vacantes o con obsolescencia edilicia o de uso.

\section{Casonas}

Es posible identificar 24 casonas, todas construidas en el segundo período. En la Figura 5 se observa la localización de las casonas dentro del ejido municipal cordobés. Una mirada general permite dilucidar dos sectores de localizaciones: 
- Sector Noroeste. En este sector se puede ver una concentración de nueve casonas extendidas de manera ciertamente dispersa en un área que se solapa con la parte más céntrica del área que delimita la localización de los barrios cercados. Todos los casos se sitúan en proximidad con arterias principales de circulación y cinco de ellas también están frente al Río Suquía, que aporta buenas características paisajístico-perceptuales como los relieves, la vegetación y un importante curso de agua.

- Sector Sur. En este sector se puede ver una concentración de 15 casonas, lo que indica que éste fue el sector predilecto para la localización de esta tipología. A su vez, este sector se encuentra más concentrado, frente a la dispersión observada para el sector noroeste. En este sector repite la localización casi exclusiva sobre arterias principales de circulación, con excepción de dos casos: la C03 (Casonas del Parque) y la C17 (Solares del Pilar).El área de localizaciones tiene un punto de solapamiento con el sector que delimitan los barrios cercados en el sur; a diferencia de este, el que definen las casonas se extiende sobre un área más céntrica y no se evidencian localizaciones fuera de la Av. Circunvalación.

FIGURA 5

Localización de las Casonas en el Municipio de Córdoba según período (1991-2010)

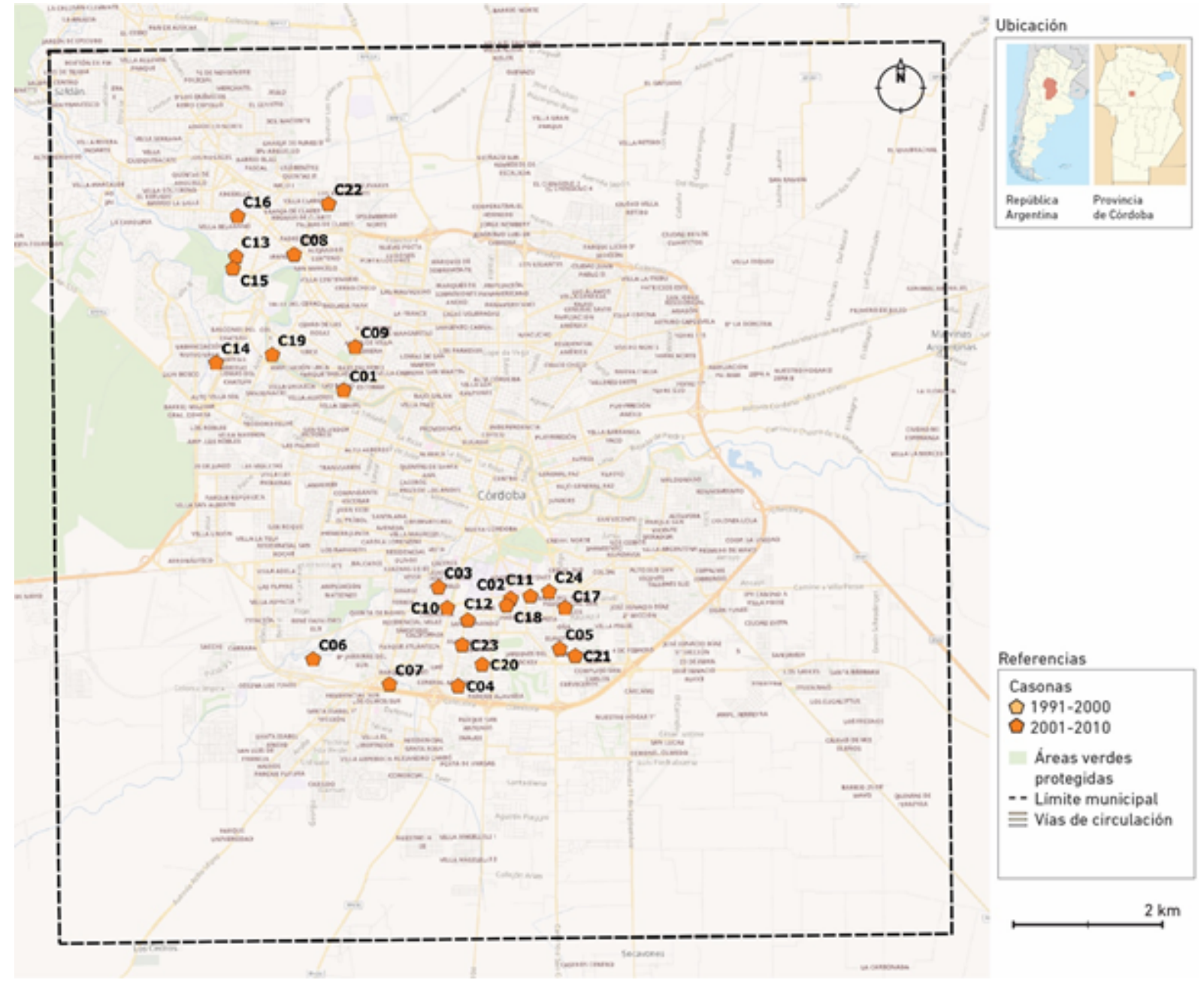

Fuente: Elaboración propia a partir de imágenes satelitales disponibles en Google Earth Pro

Las casonas se localizan sobre tejidos urbanos muy consolidados y con buenos servicios e infraestructura urbana, buscando aprovechar predios vacantes o con obsolescencia edilicia o de uso. 


\section{Una mirada general sobre los barrios cerrados}

Los análisis de las Figuras 2, 3, 4 y 5 evidencian patrones de localización de las tipologías que se imprimen sobre el espacio urbano dibujando corredores, sectores y, para el caso más cercano al centro, anillos. En la Figura 6 se superponen estos puntos y se termina de visualizar que los lugares preferidos para la localización de las cuatro tipologías de barrios cerrados son los de la zona sur y la zona noroeste de la ciudad.

La identificación de estas localizaciones abona la hipótesis de que las intervenciones de las empresas de desarrollo urbano en la Ciudad de Córdoba eligen invertir en los sectores aledaños a barrios tradicionales y en los sectores de la ciudad que concentran una gran cantidad de la población de altos ingresos. Estos sectores cuentan con infraestructura eficiente de transporte privado y buenas características paisajísticas perceptuales. Más aún, están mayoritariamente alejadas de los barrios más pobres.

Las casonas, los barrios cercados y las URE ocupan sectores bastante similares; no obstante, mientras las casonas tienen mayor presencia en el sector sur, los Barrios Cerrados la tienen en el sector noroeste. A la vez, las URE se inician en múltiples sectores de la ciudad, pero a partir del 2001 se consolidan en el sector sur.Más allá de estas diferencias, es posible deducir que la estrategia de las empresas de desarrollo urbano es localizar los barrios cerrados sobre los espacios ricos de la población; es decir, replican así una lógica de contigüidad.

\section{FIGURA 6}

Localización de tipologías de barrios cerrados en el Municipio de Córdoba según período (1991-2010)

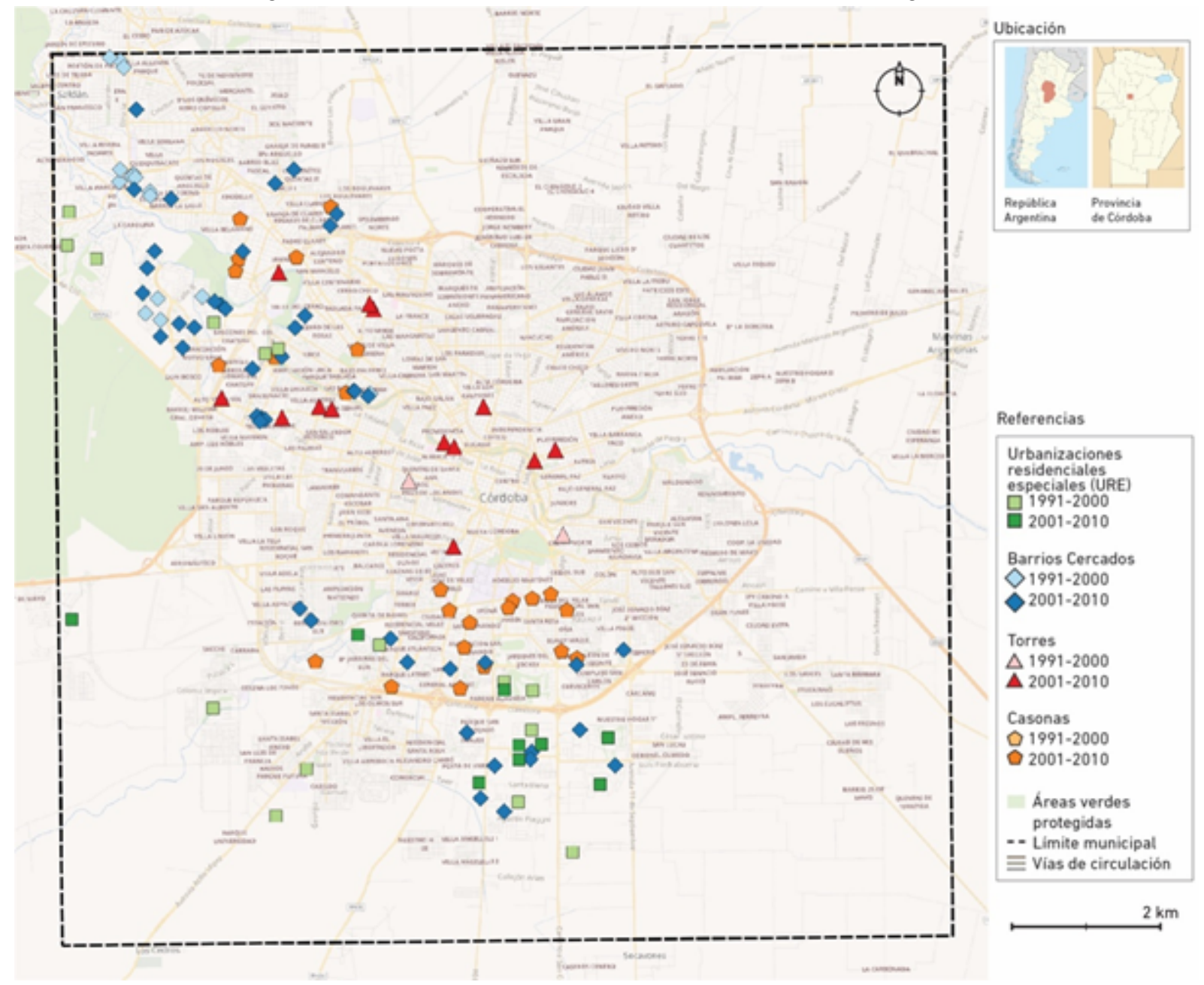

Fuente: Elaboración propia a partir de imágenes satelitales disponibles en Google Earth Pro 


\section{REFLEXIONES FINALES}

La evidencia que muestran los patrones de localización de barrios cerrados sobre el espacio urbano cordobés replica una intensificación del desarrollo polarizado que, según Borsdorf (2003), había caracterizado a las ciudades latinoamericanas durante la segunda fase de urbanización, hasta la década del 70. No obstante, a diferencia de lo que el autor señala, para el caso de la Ciudad de Córdoba el proceso de fragmentación residencial privado no se imprime sobre todo el espacio urbano sino sobre lugares específicos con características socioeconómicas similares a las que se busca incorporar.

Entonces, el análisis de los patrones de localización de barrios cerrados que se muestra en la Figura 6 verifica la hipótesis de Marengo (2004) sobre la localización de la producción privada en sectores contrapuestos a la producción pública. Lo anterior parece indicar que, durante el recorte temporal en cuestión en la Ciudad de Córdoba, las acciones privadas de desarrollo urbano intensifican la división ciudad rica - ciudad pobre en la escala urbana, y que posibles estudios en una escala menor no encontrarían contrastes socioeconómicos abruptos dentro de la trama urbana de manera generalizada, sino más bien un entorno socioeconómico relativamente homogéneo.

En este sentido, la aparición de un modelo residencial fragmentado en la Ciudad de Córdoba presta mayores similitudes con las tendencias múltiples que se sobreimprimen sobre un modelo preexistente (Caldeira, 2007) y que intensifican la división social del espacio a escala urbana (Ciccolella, 2014; De Mattos, 2010; Duhau y Giglia, 2008).

\section{ReFERENCIAS}

Borsdorf, A. (2003). Cómo modelar el desarrollo y la dinamica de la ciudad latinoamericana. EURE, 29(86), 37-49. Recuperado a partir de http://dx.doi.org/10.4067/S0250-71612003008600002

Borsdorf, A., Sánchez, R. y Marchant, C. (2008). Aprendiendo de los errores: La necesidad de cambios a la política nacional de vivienda en ciudades intermedias chilenas. Scripta Nova: Revista Electrónica de Geografía y Ciencias Sociales, 12(47). Recuperado a partir de https://doi.org/10.1344/sn2008.12.1476

Caldeira, T. (2007). City of Walls: crime, segregation and citizenship in São Paulo. Los Angeles: University of California Press.

Carmona, M. y Burgess, R. (Eds.) (2001). Strategic Planning \& Urban Projects: Responses to Globalization from 15 cities. Delft: Delft University Press.

Ciccolella, P. (2014). Metrópolis latinoamericanas: más allá de la globalización. Buenos Aires: Café de las Ciudades.

De Mattos, C. A. (2010). Globalización y metamorfosis metropolitana en América Latina. De la ciudad a lo urbano generalizado. Revista de Geografia Norte Grande, 104(47), 81-104. Recuperado a partir de http://dx.doi.org/1 0.4067/S0718-34022010000300005

Duhau, E. y Giglia, A. (2008). Las reglas del desorden: habitar la metrópoli. Ciudad de México: Siglo XXI Editores.

Frediani, J. C. (2008). Lógicas y tendencias de la expansión residencial en áreas periurbanas de ciudades medias. (Tesis de doctorado). Universidad Nacional de La Plata, La Plata.

Frediani, J. C. (2009). Las nuevas periferias en el proceso de expansión urbana. El caso del Partido de La Plata. Geograficando, 5(5), 1-23.Recuperado a partir de https://www.geograficando.fahce.unlp.edu.ar/article/view/G EOv05n05a05

Frediani, J. C. y Matti, C. (2007). Transformaciones urbanas en el partido de La Plata desde los años '90. ¿Hacia un modelo de ciudad compacta o difusa? Geograficando, 2(2), 179-199. Recuperado a partir de https://www.geog raficando.fahce.unlp.edu.ar/article/view/GEOv02n02a10

Janoschka, M. (2002). El nuevo modelo de la ciudad latinoamericana: fragmentación y privatización. EURE, 28(85), 11-20. Recuperado a partir de http://dx.doi.org/10.4067/S0250-71612002008500002 
Lemma, M. (2017). Gestión municipal y planificación urbana en Córdoba, Argentina (1983-2011). Urbe. Revista Brasileira de Gestão Urbana, 9(3). Recuperado a partir de https://doi.org/10.1590/2175-3369.009.003.AO07

Lemma, M. (2020a). Entre el modelo de ciudad compacta y las lógicas empresariales. Fragmentación del espacio urbano residencial en la Ciudad de Córdoba, 1991-2010. (Tesis inédita de doctorado). Universidad Nacional de General Sarmiento, Buenos Aires.

Lemma, M. (2020b). Hacia una definición y tipología de barrios cerrados. Caso de estudio: Córdoba, Argentina, 1991-2010. Estudios Del Hábitat.

Marengo, C. (2004). Una aproximación a la segregación residencial, como punto de partida en la formulación de políticas. Revista INVI, 19(50), 165-181.

Maya, M. A. (2017). El crecimiento de urbanizaciones cerradas y la fragmentación socioterritorial en la ciudad de Mar del Plata. Pasado Abierto, 6, 218-240.

Meyer, K. y Bähr, J. (2001). Condominios in Greater Santiago de Chile and their impact on the urban structure. Die Erde, (132), 293-321.

Argentina. Municipalidad de Córdoba (1991). Urbanización Residencial Especial. Recuperado de https://servicios2.c ordoba.gov.ar/DigestoWeb/Page/BuscarDocumento.aspx

Argentina. Municipalidad de Córdoba (2003). Formulación de lineamientos alternativospara el plan urbano ambiental. Recuperado de https://servicios2.cordoba.gov.ar/DigestoWeb/Page/BuscarDocumento.aspx

Argentina. Municipalidad de Córdoba (2006). Area de exclusión de URE. Recuperado de https://servicios2.cordoba. gov.ar/DigestoWeb/Page/BuscarDocumento.aspx

Oliveira Goulart, J. y De Oliveira Gonçalves, C. (2019). Enclaves fortificados e segregação urbana: a dinâmica contemporânea de urbanização de Ribeirão Preto. Risco.Revista de Pesquisa Em Arquitetura e Urbanismo, 17(2), $41-59$.

Pallud, P. (2010). Las Urbanizaciones Privadas Cerradas en Santo Tomé, Santa Fe. Pampa, (6), 37-58. Recuperado a partir de https://doi.org/10.14409/pampa.v1i6.3176

Prieto, M. B. (2012). Segregación socio-residencial en ciudades intermedias. El caso de Bahía Blanca - Argentina. Breves Contribuciones del I.E.G., 23, 129-156.

Argentina. INDEC (2001) Censo 2001. Recuperado de https://www.indec.gob.ar/

Argentina. INDEC (2010) Censo 2010. Recuperado de https://www.indec.gob.ar/

Roitman, S. (2005). Who segregates whom? The analysis of a gated community in Mendoza, Argentina. Housing Studies, 20(2), 303-321. Recuperado a partir de https://doi.org/10.1080/026730303042000331790

Sabatini, F. y Cáceres, G. (2001). Segregación residencial en las principales ciudades chilenas: Tendencias de las tres últimas décadas y posibles cursos de acción. EURE, 27(82), 21-42. Recuperado a partir de http://dx.doi.org/1 $0.4067 /$ S0250-71612001008200002

Secchi, B. (2005). Ciudad moderna, ciudad contemporánea y sus frutos. En A. M. Ramos (Ed.), Lo urbano en 20 autores contemporáneos (pp. 145-158). Barcelona: Universidad Politècnica de Catalunya.

Segura, R. (2014). Desigualdades socio-espaciales en ciudades latinoamericanas. Dos problemas, una paradoja y una propuesta. Aporia Jurídica. Revista de Estudios Jurídicos y Sociales, 7(6), 11-43.

Usach, N. y Garrido Yserte, R. (2009). Globalización y ciudades en América Latina. ¿Es el turno de las ciudades intermedias en la Argentina? Revista Documentos y Aportes en Administración Pública y Gestión Estatal, 13,7-38.

Valles, M. S. (1999). Técnicas cualitativas de investigación social. Reflexión metodológica y práctica profesional. Madrid: Síntesis.

\section{Notas}

1 El nombre oficial del municipio es, según lo establecido en su Carta Orgánica, "Municipio de la Ciudad de Córdoba”. En este trabajo, con el propósito de facilitar la lectura, se refiere a él como Ciudad de Córdoba. En estos casos, se está puntualizando al área político-administrativa o a su ejido municipal, que conforma un cuadrado de $24 \mathrm{~km} \mathrm{de} \mathrm{lado.} \mathrm{En}$ 
este sentido, se diferencia con la nomenclatura del Área Metropolitana de Córdoba y de la Provincia de Córdoba, que representan otros territorios. 